\title{
SOBRE LA RELACIÓN POSTMODERNA ENTRE \\ PENSAR Y OBRAR Y LA INFLUENCIA DE LOS \\ MEDIOS DE COMUNICACIÓN
}

JuAN RAMÓN MuÑOZTORRES

Profesor titular de Periodismo. Universidad Complutense de Madrid

Resumen

Las ideas abstractas rigen nuestra actuación cada vez menos. Nuestra manera habitual de actuar -movida más por impulsos y deseos que por juicios teóricos- es la que acaba generando un discurso legitimador de la propia conducta. La mayor parte de los problemas morales contemporáneos son consecuencia, en buena medida, de la crisis del pensamiento, tan característica de la llamada época postmoderna. El presente artículo se propone ofrecer algunas consideraciones respecto a la interacción entre pensamiento y acción propia de la postmodernidad, y de qué manera inciden en ella los medios de comunicación.

\section{Abstract}

Abstract ideas rule our behaviour less and less all the time. Our usual way of behaving -driven more by impulses and desires than by theoretical judgements-yields a discourse which tends to legitimize the conduct itself a posteriori. Most contemporary moral problems are caused, to a large extent, by the crisis of theoretical thinking, which is characteristic of the so-called post-modern era. This article intends to offer some insight on the interaction between thinking and action, and to what extent mass-media play a role in this interaction. 


\section{INTRODUCCIÓN}

En esa obra genial titulada Cartas del diablo a su sobrino, de Clive Staples Lewis, se puede leer esta recomendación que da el viejo y experimentado diablo Escrutopo a su sobrino, novato en las artes de la tentación: "Tomo nota de lo que dices acerca de orientar las lecturas de tu paciente y de ocuparte de que vea muy a menudo a su amigo materialista. Pero ìno estarás siendo un poco ingenuo? Parece como si creyeras que los razonamientos son el mejor medio de librarle de las garras del Enemigo. Eso podría haber sido así, si hubiera vivido hace unos pocos siglos. En aquella época, los hombres todavía sabían bastante bien cuándo estaba probada una cosa, y cuándo no; y si estaba probada, la creían de verdad. Todavía unían el pensamiento a la acción, y estaban dispuestos a cambiar su modo de vida como consecuencia de una cadena de razonamientos. Pero ahora, con la prensa semanal y otras armas semejantes, hemos cambiado mucho todo eso. Tu hombre se ha acostumbrado, desde que era un muchacho, a tener dentro de su cabeza, bailoteando juntas, una docena de filosofías incompatibles. Ahora no piensa, ante todo, si las doctrinas son 'ciertas' o 'falsas', sino 'académicas' o 'prácticas', 'superadas' o 'actuales', 'convencionales' o 'implacables" (Lewis, 1991: 11).

Lewis señala aquí con gran perspicacia un fenómeno característico de la llamada época postmoderna: la manifiesta incoherencia entre las ideas que sostenemos y el modo en que actuamos. Esta incoherencia procede no sólo de que el pensamiento no condiciona tanto la acción como ocurría, por lo general, en siglos anteriores, sino de que su incidencia en la vida tiende a ser progresivamente menos relevante. Cada vez menos son las ideas abstractas lo que nos lleva primariamente a actuar de una $u$ otra manera. Al contrario, la manera habitual de actuar -movida más por impulsos y apetencias que por juicios teóricos- es la que acaba generando un discurso teórico legitimador de la propia conducta.

En relación con esta incoherencia entre acción y pensamiento, Lewis atribuye de paso un papel decisivo a los medios de comunicación (la "prensa semanal", dice él), si bien en 1942 -año de publicación de la obra citada- el peso de los medios en la sociedad británica era incomparablemente menor del que tienen en la actualidad. Poco puede sorprendernos esta afirmación, puesto que es conocida desde muy antiguo la influencia de los medios sobre los comportamientos individuales y sociales. En este artículo, quisiera ofrecer algunas consideraciones respecto a la interacción entre pensamiento y acción propia de la postmodernidad, y la incidencia que tienen en ella los medios de comunicación.

\section{INTERDEPENDENCIA DE PENSAMIENTO Y ACCIÓN}

Tal vez sea poco precisa, aunque sustancialmente verdadera, la afirmación de que, a medida que ha ido avanzando el siglo XX, la vida del hombre se ha ido haciendo cada vez menos reflexiva. Se ha convertido en un lugar común -porque es verdad- que la vida contemporánea está dominada, particularmente en Occidente, por el ritmo trepidante y por la omnipresencia de mensajes icónicos. Uno y otra dejan poco margen para la reflexión. 
Considerando ahora lo segundo, se suele afirmar con razón que vivimos en una cultura de la imagen, que ha conformado en el pasado reciente -y lo seguirá haciendo cada vez más en el futuro- los hábitos intelectuales y morales de millones de personas. Aunque esta influencia presenta aspectos positivos evidentes, también acarrea consecuencias muy negativas, entre las que destaca la tendencia a fomentar actitudes de pasividad intelectual y de adormecimiento de la capacidad crítica'. Hay muchos indicadores en este sentido. Por ejemplo, las encuestas sobre hábitos de lectura muestran que la mayor parte de la gente lee muy poco ${ }^{2}$. Asimismo, sin necesidad de recurrir a estudios demoscópicos, es fácil percatarse de que los saberes teóricos no están de moda: en nuestra época impera el "pensamiento débil"3 y en ella la razón instrumental ha desplazado ampliamente a la razón especulativa o contemplativa. Así las cosas, es claro que el discurso abstracto ha perdido buena parte de su capacidad de influir en la vida personal y colectiva, puesto que ha cedido terreno en favor de otro tipo de saberes técnico-instrumentales, de carácter pragmático.

De lo anterior no se sigue, obviamente, la negación de valiosas aportaciones contemporáneas al pensamiento en disciplinas como la física, la hermenéutica o la sociología, por poner ejemplos. Ahora bien, de nuevo a riesgo de incurrir en generalización excesiva, creo que se puede afirmar que el modo de pensar -la visión del mundo y de la vida- ha cambiado drásticamente, aunque de forma paulatina, a lo largo del siglo XX. Por supuesto que en el pasado se han sucedido concepciones muy diversas, y hasta contradictorias, del hombre y de su habitar en el mundo. Pero, en términos generales, nuestra época se caracteriza por haber roto buena parte de sus vínculos con las cosmovisiones heredadas, no sólo en el terreno filosófico, científico o literario, sino también en el plano de la economía o de la política ${ }^{4}$.

Particularmente relevante para el tema que nos ocupa es el alejamiento, o claro abandono -según los casos-, de los principios que conforman lo que se podría llamar la civilización cristia-

\footnotetext{
1 Desde la Escuela de Francfort hasta nuestros días, son numerosos los autores que han tratado acerca de los efectos intelectuales negativos que tiene para muchas personas el uso indiscriminado y excesivo de los medios audiovisuales. En los últimos años, Sartori, p. ej., ha mostrado convincentemente -aunque tal vez con cierta desmesura- cómo la televisión tiende a fomentar esquemas reduccionistas, que dificultan la comprensión de abstracciones y de conceptos, y va atrofiando la capacidad de abstracción. Cfr. SARTORI, G., Homo videns. La sociedad teledirigida. Madrid, Taurus, 1988 (ed. o.: 1987).

2 Según una encuesta sobre hábitos de lectura en España, promovida por el Ministerio de Educación, Cultura y Deportes y la Federación de Gremios de Editores de España y publicada en 2000 , el $42 \%$ de los españoles no lee libros nunca o casi nunca.

3 Esta expresión, acuñada por Gianni Vattimo, denomina la situación intelectual típicamente postmoderna, que rechaza cualquier fundamentación última de carácter metafísico. Vid., p. ej., VATTIMO, G., El fin de la modernidad. Nihilismo y hermenéutica en la cultura posmoderna. Barcelona, Gedisa, 1987.

${ }^{4}$ Hasta tal punto es clara esta ruptura que, en el campo del pensamiento político, el declive de su influencia en las actuaciones concretas ha dado lugar a tesis como la del "final de las ideologías". Aunque este tema fue abordado por primera vez por el sociólogo estadounidense Daniel Bell a finales de los cincuenta, al tratar sobre la convergencia de los sistemas capitalista y socialista, se ha convertido en un lugar común a partir de la caída del Muro de Berlín en 1989. En los últimos años, la expresión transmite la idea de que, en la mayor parte de Occidente, ya no hay grandes diferencias, como en el pasado, en las maneras de ver los problemas del mundo y de enfocar sus soluciones $y$, con frecuencia, se asocia esta situación al llamado "pensamiento único".
} 
na, que ha marcado el devenir de Occidente en los últimos veinte siglos. Este alejamiento o abandono se manifiesta en dos planos diversos, estrechamente conectados. Por una parte, en el campo del pensamiento, las bases de la filosofía realista de origen aristotélico han quedado oscurecidas y descalificadas por una mezcla más o menos sincrética de doctrinas que van desde el racionalismo cartesiano, al empirismo y el positivismo, pasando por el idealismo, el nihilismo o el existencialismo. Por otra, en el plano de la conducta, amplios sectores de sociedades de larga y profunda tradición cristiana han dejado de regirse poco a poco según las ideas y valores de la fe religiosa, que han sido desplazados por otros de corte materialista y hedonista.

Una de las muchas pruebas de esta ruptura con el saber compartido de siglos anteriores se manifiesta -como observa Alasdair Maclntyre- en que los debates morales contemporáneos son interminables (Maclntyre, 1987: 14-18). Según este autor, aunque usemos términos de larga tradición, muchos conceptos morales contemporáneos se han vaciado de contenido, son "fragmentos de un esquema conceptual, partes a las que ahora faltan los contextos de los que derivaba su significado"s. La consecuencia lógica-como señala Maclntyre- es que tales debates carecen de solidez conceptual y están regidos, más por sentimientos y preferencias arbitrarias, que por argumentos de validez racionalmente ponderable y confrontables entre sí. Si este diagnóstico es acertado, como parece, ¿qqué incidencia tiene, entonces, el pensamiento en la vida? lación estrecha entre pensar y obrar, o caminamos hacia una escisión todavía mayor entre uno y otro?

Al plantear debates éticos sobre los problemas más diversos que aquejan al hombre de nuestra época, casi inevitablemente se escucha hablar de "crisis de valores", como si los valores en su conjunto -y no un tipo particular de ellos- estuvieran efectivamente atravesando una situación dificultosa. No hace falta reflexionar mucho para advertir que el hombre se mueve siempre por valores (tengan o no fundamento, y en mayor o menor grado, en el ser de las cosas). La expresión encierra, pues, una sinécdoque -no exenta de cierto tono eufemístico- mediante la cual se toma un tipo de valores (normalmente los de cuño cristiano), por el conjunto de valores. Y no sólo eso, sino que el término "valor" queda reducido a sus aspectos morales, en detrimento de otros más ligados a la dimensión cognoscitiva humana. Sin embargo, la evidencia de que la crisis de valores es eminentemente moral, no debería oscurecer el hecho -tal vez menos evidente- de que tiene también hondas raíces intelectuales, que se manifiestan de muchas maneras.

Es en esta dirección en la que apuntan -a mi parecer- las palabras de Lewis citadas al principio: la estrecha relación que une negativamente la renuncia a pensar con el obrar. A diferencia de lo que ocurría en épocas pasadas, en las que los hombres "estaban dispuestos a cambiar su modo de vida como consecuencia de una cadena de razonamientos", en la actualidad esto cada vez sucede menos. El problema de la verdad -y otros temas fundamentales- ha quedado relegado 
y se ha vuelto "teórico" en el peor sentido del término ${ }^{6}$, es decir, irrelevante para la vida diaria. Cada vez más personas se dejan llevar de ideas y valores que "flotan" en el ambiente, más a causa de la influencia del ejemplo ajeno, que de la reflexión intelectual. Por eso, no es infrecuente escuchar que ciertas personas justifican sus cambios de conducta en términos, no de "verdadero" o "falso", "bueno" o "malo", sino -con palabras que parecen sugeridas por el diablo Escrutopo- de "progresista" o "reaccionario", de "moderno" o "anticuado".

A primera vista, pues, podríamos pensar que la divergencia creciente entre pensamiento y acción tiene su causa principal-si no exclusiva- en factores morales, independientes de los de índole intelectual. Sin embargo, aceptar esto sería simplificar inadecuadamente el problema. Por una parte, la falta de honradez intelectual es, en efecto, una causa decisiva a la hora de explicar la ineficacia del pensamiento para dirigir la conducta ${ }^{7}$. Cuando esto ocurre en los pequeños o grandes episodios de la vida de cualquier persona común, la voluntad deforma el juicio de la inteligencia, a la que recurre a posteriori para justificar lo previamente elegido. Ahora bien, atribuir toda la responsabilidad del obrar a la voluntad sería desconocer que la voluntad no funciona separadamente de la inteligencia. El mal moral requiere también -como el bien- del concurso de ésta. De ahí que, si como sucede contemporáneamente, la inteligencia se cercena a sí misma declarando falsamente la imposibilidad de conocer con verdad, entonces la actuación moral deja de juzgarse por razones de verdad y bondad, para quedar al arbitrio de criterios temporales (anticuada/novedosa), relativos a la opinión de los demás (aceptada/rechazada), o a las propias preferencias e impulsos (placer/dolor).

Así pues, respondiendo a las preguntas acerca de la incidencia del pensar en el obrar antes planteadas, es preciso recordar una evidencia que tiende a difuminarse en nuestro tiempo: el pensamiento (o la renuncia a él) influye de manera decisiva en el obrar moral (y viceversa: éste condiciona, reforzando o modificando, el modo de pensar). Es preciso recordar que inteligencia y voluntad, pensar y querer, son fuerzas que mueven al hombre de manera simultánea y entrelazada, y que ambas se realimentan recíprocamente. Los clásicos -tanto cristianos como no cristianos- tenían muy presente que una voluntad corrompida entorpece o imposibilita el pensar con rectitud, tanto como una inteligencia equivocada no puede guiar certeramente a la mera "buena voluntad" 8 .

\footnotetext{
- Conviene recordar la distinción entre discurso teórico y elucubración: el primero ilumina lo real desde el ángulo superior de la abstracción, busca lo universal y necesario que se da en lo particular, sin que sea por ello irreal; la elucubración, en cambio, es una suerte de "malabarismo" intelectual, despreocupada de dar razón de la realidad que se presenta al hombre, cerrada sobre sí misma y que tiende a autolegitimarse sin referentes reales. Con frecuencia, se toma por teoría lo que no pasa de ser una elucubración. De ahí que el desprestigio de la segunda tienda a hacerse extensivo, injustificadamente, a la primera.

Es la falta de honradez intelectual la diferencia esencial que separa a un "sinvergüenza auténtico" de un "auténtico sinvergüenza". Cfr. el lúcido y brillante ensayo de Jacinto Choza, "Elogio de los grandes sinvergüenzas", en Nuestro Tiempo, nn. 229-230, julio-agosto 1973, pp. 83-87.

8 Aristóteles señala en diversos lugares de sus obras la estrecha relación entre pensar y obrar. Por ejemplo: "[...] no es posible ser bueno en sentido estricto sin la prudencia, ni prudente sin la virtud moral" (ARISTOTELES, Ética a Nicómaco, 1144 b 30-32; ed. de M. Araujo y J. Marías, Madrid, Centro de Estudios Constitucionales, 1985; ed. o.: 1949).
} 
En cambio, hoy en día, tendemos a olvidar que el conocimiento teórico es condición de posibilidad del buen obrar práctico"; es decir, que para obrar bien, hay que pensar bien (y, viceversa: que para pensar bien, hay que obrar bien).

\section{TRES CAUSAS INTELECTUALES DE LA DIVERGENCIA ENTRE PENSAMIENTO Y ACCIÓN}

Pienso que, con lo dicho hasta aquí, queda descartado el simplismo -no infrecuente- que lleva a plantear las crisis de valores postmodernas como una lucha en la que los valores buenos han de contrarrestar a los malos, al modo en que un antibiótico combate una infección bacteriana. En asuntos complejos, como éste, no caben soluciones tan simples. Sin duda, promover valores positivos es decisivo para combatir valores negativos, pero esto no eliminaría el problema sin más. Para empezar, porque la calificación de un valor como positivo o negativo depende esencialmente de la visión del hombre y del fin de la vida que se tenga.

Como he afirmado antes, buena parte de la desorientación intelectual y de los males morales contemporáneos, principalmente en los países occidentales, derivan de la ruptura con los principios y valores que han conformado la cosmovisión cristiana durante siglos. Sería arduo y prolijo justificar de manera incontrovertible esta tesis. Entre otras razones porque exigiría un acuerdo previo sobre lo que se entiende por cosmovisión cristiana, por desorientación intelectual y por mal moral. Quede, pues, a la apreciación del lector la verdad de la afirmación. Ahora bien, sin necesidad de entrar en consideraciones de esta naturaleza -que exceden completamente el propósito y los límites de estas páginas-, creo que se pueden apuntar esquemáticamente algunas causas de la incoherencia entre pensamiento y acción contemporáneas, vistas desde la perspectiva del conocimiento (el énfasis en la dimensión intelectual de la cuestión pretende contrapesar algunos análisis simplistas en los que, a veces, se incurre). Más concretamente, acometeré a continuación un rápido examen de esta cuestión desde tres ángulos diferentes, estrechamente conectados:

1. desconfianza en la capacidad de la inteligencia humana

2. predominio de una mentalidad empírico-positivista

3. hegemonía de un pensamiento relativista y escéptico, sobre lo que no es comprobable empíricamente

\section{Desconfianza en la capacidad de la inteligencia humana}

En primer lugar, empezaré por mencionar la desconfianza en la capacidad de la razón para descubrir las verdades más profundas y universales sobre la existencia del ser humano. El ago-

\footnotetext{
9 Acerca de este particular, vid., p. ej.: VICENTE ARREGUI, J., "La condición de posibilidad del conocimiento práctico", en Anuario Filosófico, 1981, vol. XIV, n. I, pp. 115-124.
} 
tamiento del proyecto racionalista ilustrado de autoemancipación del hombre, eje de la modernidad, ha ido dando paso progresivamente a un periodo postmoderno caracterizado por una actitud fuertemente escéptica sobre las potencialidades de la inteligencia en relación con esas grandes cuestiones de la vida humana, acerca de las cuales la Humanidad viene reflexionando desde antiguo.

A este respecto, el Papa Juan Pablo II ha hecho un diagnóstico muy atinado en su encíclica Fides et Ratio: "mientras por una parte la reflexión filosófica ha logrado situarse en el camino que la hace cada vez más cercana a la existencia humana y a su modo de expresarse, por otra tiende a hacer consideraciones existenciales, hermenéuticas o lingüísticas que prescinden de la cuestión radical sobre la verdad de la vida personal, del ser y de Dios. En consecuencia han surgido en el hombre contemporáneo, y no sólo entre algunos filósofos, actitudes de difusa desconfianza respecto de los grandes recursos cognoscitivos del ser humano. Con falsa modestia, se conforman con verdades parciales y provisionales, sin intentar hacer preguntas radicales sobre el sentido y el fundamento último de la vida humana, personal y social" ${ }^{10}$.

Pienso que este análisis es de gran lucidez: en nuestras sociedades avanzadas hay una evidente y considerable aversión por lo abstracto y lo no útil, por la reflexión y el razonamiento filosóficos. Al margen de lo acertado o no de las respuestas que se puedan dar a las cuestiones centrales de la vida humana, es inquietante la frecuente actitud previa de rechazo frente a ellas, el prejuicio que lleva a tildarlas gratuitamente como "bizantinas", de escasa o nula relevancia para la vida "real". De ahí que, para muchas personas, lo "razonable" sea huir de plantearse problemas "metafísicos", es decir, no "reales"11, y de pretensiones :utópicas (el logro de la verdad humanamente posible). Baste considerar, por ejemplo, cómo, en nuestros días, la pregunta por la verdad queda descalificada de entrada como no científica, lo que viene a significar inasequible para la mente humana. Unas palabras de Guillermo de Baskerville, el protagonista de El nombre de la rosa, la célebre novela de Umberto Eco, ilustran y resumen certeramente esta posición escéptica: "la única verdad consiste en aprender a liberarnos de la insana pasión por la verdad"(Eco, 1983: 595).

Afirmaciones como la anterior, y otras en la misma línea acerca de la inaccesibilidad de la verdad, plantean un serio problema: son declaraciones que se autopostulan como verdaderas, lo

\footnotetext{
10 JUAN PABLO II, Fides et Ratio, n. 5. Cfr. también el n. 55.

$"$ Sobre el sentido coloquial que solemos dar a la palabra "real" encuentro muy iluminador el siguiente pasaje de otra de las cartas de Escrutopo: "Habrás notado que los tenemos [a los humanos] completamente confundidos sobre el significado de la palabra 'real'. Se dicen unos a otros, acerca de una gran experiencia espiritual: 'Lo que realmente ocurrió fue que escuchaste un poco de música en un edificio iluminado'; aquí 'real' significa los desnudos hechos físicos, separados de los demás elementos de la experiencia que, efectivamente, tuvieron. Por otra parte, también dirán: 'Está muy bien hablar de ese salto desde un trampolín alto, ahí sentado en un sillón, pero espera a subir allá arriba y verás lo que es realmente: aquí 'real' se usa en el sentido opuesto, no para referirse a los hechos físicos (que ya conocen, mientras hablan del asunto sentados en sillones), sino al efecto emocional que tales hechos tendrán sobre la conciencia humana. Cualquiera de estas acepciones de la palabra podría ser defendida; pero nuestra misión consiste en hacer que las dos estén funcionando a la vez, de manera que el valor emocional de la palabra 'real' pueda usarse ahora en un sentido, ahora en otro, según nos convenga" (LEWIS, C.S., op. cit., p. 153-154).
} 
que significa que se autorrefutan. No se puede negar el concepto de verdad, sin presuponerlo mínimamente; sin tal concepto, la misma negación no podría ni tan siquiera ser entendida. Rechazar los problemas metafísicos es ya una postura metafísica y, por tanto, incurre en contradicción consigo misma.

Cuestión aparte es que quienes se contradicen tan notoriamente sean -o quieran ser- conscientes de sus contradicciones. No por casualidad, la descalificación como irreales o irresolubles de algunas "grandes cuestiones" suele ir unida a la afirmación del valor de realidad de asuntos pragmáticos y utilitarios, orientados al placer, al dinero y al poder. Nuevamente, se nos hace presente que inteligencia y voluntad no funcionan en paralelo, sino de una forma entrelazada que se retroalimenta. De cualquier manera, en la persecución constante de estos tres grandes valores, aceptados sin discusión y queridos con vehemencia, la razón instrumental es la única que goza de prestigio y que ha experimentado una clara hipertrofia.

Ahora bien, la renuncia a pensar y las tesis escépticas no pueden ser tomadas en serio -si se pretende un mínimo de coherencia ${ }^{12}-$, ni permiten vivir según ellas: la vida humana no puede desarrollarse sin conocimiento. De ahí que el rechazo a la razón teórica no pueda ser tan radical que permita desentenderse por completo de los criterios de validez de nuestro conocimiento, es decir, del problema de la verdad. Es inevitable, entonces, adoptar algún tipo de criterio -más o menos fundado y consciente- para distinguir entre juicios válidos y aquéllos que no lo son. De entre las diversas respuestas que se han dado históricamente sobre el problema de la validez del conocimiento, hay dos que, a mi parecer, son genuinamente postmodernas: el pensamiento empírico-positivista, por un lado, y el relativista, por otro. Ambas doctrinas -por paradójico que pueda resultar- suelen darse inseparablemente unidas, como si se tratara de las dos caras de una misma moneda.

\section{Predominio de una mentalidad empírico-positivista}

En línea con lo anterior, resulta bastante evidente el predominio, en nuestra época, de la mentalidad empírico-positivista, que sólo juzga verdadero lo comprobable empíricamente, e invalida como irracionales o "literarias" las preguntas por el sentido de la vida y otras cuestiones de carácter ético o metafísico. Este rechazo por lo no fáctico y experimentable supone una toma de postura filosófica reduccionista, que se autopropone como evidente ("sólo lo verificable fácticamente es verdadero"), pese a que incurre en contradicción con su propio principio (puesto que su tesis central no es comprobable experimentalmente).

Como es sabido, esta manera de pensar tiene su origen en la filosofía empirista del XVII. No se trata, pues, de ideas surgidas en la época contemporánea. No obstante, una diferencia sustan-

\footnotetext{
12 Ya Aristóteles mostró que el escepticismo radical es incoherente e insostenible: "con sólo que diga algo el adversario [i.e.: el escéptico]; y, si no dice nada, es ridículo tratar de discutir con quien no puede decir nada [...], pues ese tal, en cuanto tal, es por ello mismo semejante a una planta" (Metafísica, 1006 a 12-15; cito por la ed. de V. García Yebra, Madrid, Gredos, 1990).
} 
cial entre el empirismo originario y su heredero es que, mientras aquel apenas traspasó los umbrales de la élite intelectual de su época, éste, en cambio, ha ido impregnando poco a poco diversos ámbitos profesionales, para acabar por instalarse sutilmente en el mundo de la vida ${ }^{13}$. En efecto, los logros indudables de la ciencia experimental y de la tecnología contemporáneas han contribuido a difundir esta mentalidad empírico-positivista, cientifista, por toda la sociedad. El único criterio de verdad socialmente aceptado en el presente es el de la ciencia experimental, por lo cual resulta muy difícil reintroducir en el debate público la cuestión de la verdad no experimental y otras afines.

Por lo que respecta a los valores morales, "en esta perspectiva, los valores quedan relegados a meros productos de la emotividad y la noción de ser es marginada para dar lugar a lo puro y simplemente fáctico. La ciencia se prepara a dominar todos los aspectos de la existencia humana a través del progreso tecnológico. [...] al marginar la crítica proveniente de la valoración ética, la mentalidad cientificista ha conseguido que muchos acepten la idea según la cual lo que es técnicamente realizable llega a ser por ello moralmente admisible"14.

\section{Hegemonía de un pensamiento relativista sobre lo no comprobable empíricamente}

Una consecuencia lógica del imperio de la mentalidad positivista es el relativismo subjetivista acerca de lo que no es objeto de ciencia experimental. Como he dicho antes, ambos asuntos están en íntima relación ${ }^{15}$. Así lo ha visto atinadamente Hilary Putnam (pese a que, en mi opinión, confunde realismo con empirismo): "En nuestros días -escribe el filósofo norteamericanotendemos a ser demasiado realistas [empiristas, es, en mi criterio, la palabra adecuada] con respecto a la física y demasiado subjetivistas con respecto a la ética, y estas tendencias están relacionadas. Es porque somos demasiado realistas en física, porque consideramos a esta última (o a alguna hipotética física futura) como La Teoría Verdadera, y no simplemente como una descripción racionalmente aceptable, adecuada a ciertos problemas y propósitos, por lo que tendemos a ser subjetivistas con respecto a las descripciones que no podemos 'reducir' a la física" (Putnam, 1988: 146).

\footnotetext{
${ }^{13}$ Comparto la percepción que Alonso tiene del vigor actual del positivismo (al que él prefiere denominar cientifismo): "sigue siendo, ante todo, una doctrina que, originándose en el dominio de la filosofía de la ciencia, se ha extendido como una corriente de opinión general. Su idea básica constituye uno de los condicionamientos principales de la vida actual, en la teoría y en la praxis. [...] En cuanto a la eficacia y la universalidad de su influjo, basta considerar que su área de influencia llega pacíficamente a todos, conjuntamente con la divulgación y la enseñanza de las ciencias en ciertos textos y manuales en los niveles básicos, medios y superiores, alcanzando así una penetración de la que pocas doctrinas podrían gloriarse" (ALONSO, C. J., La agonía del cientifismo, Pamplona, Eunsa, 1999, p. 27).

14 JUAN PABLO II, Fides et Ratio, n. 88.

${ }_{15}$ He desarrollado con cierto detenimiento esta idea en: "Objetividad y verdad. Sobre el vigor contemporáneo de la falacia objetivista", Revista de Filosofía de la Universidad Complutense de Madrid, 2002, vol. 27, n. 1, pp. 161-190.
} 
Dada la estrecha conexión entre positivismo y relativismo, poco puede extrañar que tan arraigado como el primero esté el segundo, en la mentalidad del hombre contemporáneo. Así lo expresa Thomas Nagel con perspicacia: "el calificativo relativista ('para mí' o 'para nosotros') se ha convertido casi en un acto reflejo, y con un sustento vagamente filosófico, es usado a menudo en forma generalizada para interpretar los desacuerdos más profundos sobre creencias o métodos como debidos a diferentes marcos de referencia, formas de pensamiento o de prácticas, o formas de vida, entre las cuales no existe ninguna forma objetiva de juicio, sino solamente una lucha por el poder. (La idea de que todo es «construido» pertenece a esa misma familia). Dado que todas las justificaciones llegan a su término con lo que las personas que las aceptan encuentran aceptable y sin necesidad de justificación ulterior, se piensa que ninguna conclusión puede reclamar validez más allá de la comunidad cuya aceptación la valida"'16.

Este relativismo subjetivista se suele dar entreverado con posturas escépticas, no sólo en ámbitos académicos, sino en el mundo de la vida corriente. En efecto, a diferencia de lo que ocurría hace sólo unas pocas décadas, cada vez es más habitual encontrar a personas que sostienen que no podemos conocer la verdad de las cosas (lo cual se suele afirmar sin caer en la cuenta de que esta misma proposición es tomada como verdadera); que no existen verdades absolutas (salvo ésta); o que la verdad es sólo fruto del consenso (lo cual no admite disenso posible, salvo acusación -autocontradictoria- de dogmatismo) ${ }^{17}$.

Dos derivaciones habituales de estas tesis son: a) se suele tomar como evidente que no es posible tener certezas absolutas (es decir, incondicionadas) sobre nada (la certeza está "mal vista", pues se asimila al dogmatismo, a la autosuficiencia y a la intolerancia); b) todo es objeto de opinión y todas las opiniones valen lo mismo, porque todas ellas son por igual refractarias a la verdad ${ }^{18}$; de donde fácilmente se concluye que todos los valores operativos son equivalentes y merecen el mismo juicio, puesto que no hay criterios racionales para discriminar entre unos y otros.

Al igual que ocurre con la verdad, otro tipo de cuestiones clave para el hombre, como la existencia de Dios, el sentido de la vida, el Más Allá, o el fundamento de la moral, se consideran, en unos

\footnotetext{
${ }^{16}$ NAGEL, Th., La última palabra, Barcelona, Gedisa, 2000, p. 16 (trad. de P. Bargallo y M. Alegre; ed. o.: The Last Word, 1997). En esta obra se ofrecen críticas bien argumentadas y brillantes, que refutan contundentemente las tesis relativistas en sus distintas variantes y enfoques.

17 Así lo hace notar Juan Pablo II: "En definitiva, se nota una difundida desconfianza hacia las afirmaciones globales y absolutas, sobre todo por parte de quienes consideran que la verdad es el resultado del consenso y no de la adecuación del intelecto a la realidad objetiva" (Fides et Ratio, n. 56).

18 "Recientemente han adquirido cierto relieve diversas doctrinas que tienden a infravalorar incluso las verdades que el hombre estaba seguro de haber alcanzado. La legítima pluralidad de posiciones ha dado paso a un pluralismo indiferenciado, basado en el convencimiento de que todas las posiciones son igualmente válidas. Este es uno de los síntomas más difundidos de la desconfianza en la verdad que es posible encontrar en el contexto actual" (Fides et Ratio, n. 5. La cursiva es mía).
} 
casos, absurdas 0 , en otros, de imposible respuesta ${ }^{19}$. En consecuencia, este tipo de temas quedan excluidos de los debates públicos, como científicamente no pertinentes o políticamente incorrectos, por lo que ni tan siquiera deben ser planteados. Y, cuando se suscitan en foros públicos, la única premisa implícitamente aceptada como evidente e indiscutible es que todas las respuestas son subjetivas (en el sentido de arbitrarias) y, por tanto, todas tienen la misma validez relativa (se suele confundir el respeto que merece la libertad de las personas para expresar su pensamiento, con la validez del mismo, que no procede exclusivamente del asentimiento que le prestan quienes lo exponen).

Estas tres formas de pensar, someramente descritas, acarrean patentes consecuencias en el obrar práctico, dada la conexión entre pensar y obrar. La presunción de que la verdad no existe, o de que no está al alcance del ser humano, o de que es relativa y cambiante, mina profundamente la posibilidad de reflexionar sobre los valores y abre la puerta a una arbitrariedad relativista, que se postula como inapelable. Así, los valores pasan a ser considerados, bien como meras apreciaciones subjetivas de cada persona (sólo dependientes de sentimientos y experiencias, de intuiciones o impulsos), bien como un conjunto de apreciaciones colectivas de índole cultural, fruto del consenso o de las cambiantes circunstancias de cada momento histórico. Poco puede sorprender entonces que la conducta personal y colectiva esté orientada más al logro de bienes sensibles, que a aquellos que perfeccionan y desarrollan al hombre en su conjunto como ser inteligente y libre.

\section{ALGUNAS CONSIDERACIONES SOBRE LA INFLUENCIA DE LOS MEDIOS DE COMUNICACIÓN}

Si ya es temerario apuntar en unas pocas páginas algunas de las principales causas intelectuales de la divergencia entre pensamiento y acción en la postmodernidad, no lo sería menos intentar exponer en detalle cuál es la responsabilidad que los medios de comunicación tienen respecto a los asuntos antes expuestos, a causa del carácter poliédrico de sus efectos sobre la sociedad $^{20}$. A la complejidad del tema hay que añadir la facilidad de incurrir, respecto a los medios, en apriorismos extremos (es decir, en posiciones "apocalípticas" o "integradas", por abusar aquí de las célebres categorías con que Eco (1968) denomina dos posturas radicales acerca de la cultura de masas).

No obstante lo anterior, pienso que merecería un reproche mayor no tocar este punto ni tan siquiera sucintamente, dada la imposibilidad de entender el mundo contemporáneo sin la existen-

\footnotetext{
${ }_{19}$ Nuevamente, unas palabras del protagonista de El nombre de la rosa ilustran bien este relativismo: "He sido un testarudo, he perseguido un simulacro de orden, cuando debía saber muy bien que no existe orden en el universo [...]. El orden que imagina nuestra mente es como una red, o una escalera, que se construye para llegar hasta algo. Pero después hay que arrojar la escalera, porque se descubre que, aunque haya servido, carecía de sentido" (ECO, U., op. cit., p. 596).

${ }^{20}$ Para un análisis global muy ponderado del papel de los medios de comunicación en el mundo contemporáneo, con sus luces y sus sombras, véase Ética en las comunicaciones sociales, documento del Pontificio Consejo para las Comunicaciones Sociales, 2000. Una exposición amplia y rigurosa -entre las muchas disponibles- de las distintas teorías sobre los efectos de los medios, en DE FLEUR, M. y BALL-ROKEACH, S., Teorías de la comunicación de masas, Barcelona, Paidós, 1993, pp. 193-376 (ed. 0.: 1989).
} 
cia de los medios. Por eso, en las páginas siguientes asumiré el reto de proponer tan sólo algunas consideraciones al respecto, necesariamente esquemáticas.

Es obvio que la gran influencia que los medios ejercen en el presente deriva, ante todo, del hecho de haberse convertido en referencia inexcusable para la vida en sociedad. Su omnipresencia y la creciente influencia que vienen ejerciendo durante décadas sobre capas cada vez más amplias de la población, los ha colocado en una posición hegemónica. Hoy en día es casi imposible sustraerse a su influencia, directa o indirecta (ni siquiera quienes pretendieran evitar cualquier "exposición" a los medios podrían soslayar el contacto con aquellas personas que están bajo su influjo directo). Por este motivo, los medios desempeñan una función de liderazgo social incuestionable, con consecuencias muy beneficiosas para la sociedad ${ }^{21}$ y otras claramente negativas. Esta función de liderazgo se desarrolla, en buena medida, gracias a su capacidad de "objetivar" lo que acontece en la sociedad, de construir y modificar la concepción colectiva de la vida y el mundo.

No obstante, no resulta fácil determinar en qué medida los medios construyen o modifican esta concepción. En la reflexión sobre el papel de los medios se ha pasado del que podríamos llamar "paradigma especular" (los medios se limitan a reflejar la realidad de la que informan), propio de los años 50 y 60, al paradigma contemporáneo, que podría denominarse "construccionista" (los medios son los principales actores responsables de la construcción social de la realidad). Me parece que ambos paradigmas deforman simplistamente el papel de los medios: por un lado, éstos no se limitan sólo a mostrar lo que acontece en la sociedad, sino que, al hacerlo, lo modifican -en mayor o menor medida- por el simple hecho de hacer "visible" a un amplio número de personas fenómenos hasta entonces poco o nada conocidos's; por otro lado, es obvio que los medios no pueden crear la realidad ex novo; incluso cuando fabrican pseudo-eventos, su actividad se apoya inevitablemente en seres y relaciones preexistentes.

Ahora bien, al margen de en qué medida los medios "crean" o "reproducen" los fenómenos sociales, lo que parece incuestionable es que establecen lo que la sociedad tiene por real y relevante en cada momento (fijan la agenda pública, por expresarlo en términos de la teoría de agenda-setting). Este enorme poder de "definir la realidad"23, ejercido principalmente mediante la selección y el enfoque, produce algunos efectos muy negativos para el modo de pensar colectivo. Me referiré brevemente a tres de ellos.

\footnotetext{
${ }^{21}$ Una valoración muy positiva, que comparto, de la contribución de los medios al bien de la sociedad, en Ética en las comunicaciones sociales, cit., nn. 6-12.

${ }^{22}$ Baste pensar en cómo una filtración de índole económica o política puede llegar a malograr una decisión importante en estos ámbitos. $O$ en cómo los medios crean personajes públicos, que pasan a tener una influencia social impensable antes de que fueran propuestos como referentes.

${ }^{23}$ Al usar esta expresión, pienso en el principio sociológico de "definición de la situación", acuñado en 1923 por uno de los padres de la Escuela de Chicago, William Isaac Thomas, y más conocido como "teorema de Thomas", que sostiene que las situaciones definidas como reales son reales en sus consecuencias; o lo que es lo mismo: que, en ciertas situaciones, lo que aparece como real -aunque no lo seatiene, para quien así lo juzga, efectos reales.
} 


\section{Lo que no aparece en los medios no existe}

En primer lugar, conviene señalar cómo los medios suelen producir en el público la impresión de que lo que no aparece en ellos no existe o, en el mejor de los casos menos, carece de importancia $^{24}$. Este efecto, aceptado ya por lo general como un lugar común, es particularmente negativo en lo que se refiere a la dimensión espiritual del ser humano y todo lo relativo a ella. Los medios no suelen ocuparse explícitamente de cuestiones filosóficas o religiosos, como las antes mencionadas, que han sido objeto de preocupación durante siglos por su centralidad para la vida humana. Y, cuando lo hacen, suelen adoptar un enfoque que trivializa los temas, o bien los reduce a sus aspectos históricos, culturales, sociológicos, etc. ${ }^{25}$ Además, la ignorancia de este tipo de temas va unida a otro "olvido", más negativo incluso que el anterior: me refiero al de un enfoque trascendente a la hora de informar de lo que sucede a diario, que queda marginado de manera sistemática como algo no presentable socialmente, políticamente incorrecto.

El problema principal que plantea este resultado de la capacidad de los medios para definir lo real, es que tiende a realimentarse en forma de bucle. Esto ya fue advertido en la década de los 70 por la socióloga alemana Elisabeth Noelle-Neuman, que denominó al fenómeno "espiral del silencio"26: si algo no aparece en los medios es porque no existe (carece de relevancia social); y si no aparece, no adquirirá relevancia social, con lo cual difícilmente podrá llegar a aparecer en los medios. Además, pensando ahora en la visión trascendente del mundo, este principio de definición funciona de manera sutil. En efecto, la negación constante por parte de los medios de la dimensión espiritual del hombre puede tener consecuencias devastadoras para muchas personas (tenemos un ejemplo todavía reciente en el totalitarismo soviético). Pero hay otra forma peor de tratar de anular la espiritualidad del hombre, que es ignorar sistemáticamente su existencia, bien temáticamente considerada, bien como perspectiva desde la que se contempla la vida en su conjunto.

\section{Lo novedoso y sensacional como criterio. El imperio de lo efímero y el efecto narcotizante}

El énfasis habitual de los medios en lo novedoso tiende a instaurar la novedad como uno de los principales criterios de valoración: se presupone que lo último, lo nuevo, lo que está a la mo-

\footnotetext{
${ }^{24}$ He aquí un nuevo ejemplo del teorema de Thomas: lo que parece inexistente, por incomparecencia, se toma por realmente inexistente.

25 "Entre las tentaciones de los medios de comunicación están el ignorar o marginar las ideas y las experiencias religiosas; tratar a la religión con incomprensión, quizá hasta con desprecio, como un objeto de curiosidad que no merece una atención seria; promover las modas religiosas con menoscabo de la fe tradicional; tratar a los grupos religiosos legítimos con hostilidad; valorar la religión y la experiencia religiosa según criterios mundanos de lo que debe ser; preferir las concepciones religiosas que corresponden a los gustos seculares a las que no corresponden; y tratar de encerrar la trascendencia dentro de los confines del racionalismo y el escepticismo. Los actuales medios de comunicación reflejan la situación posmoderna del espíritu humano, encerrado «dentro de los límites de su propia inmanencia, sin ninguna referencia a lo trascendente» (Fides et ratio, 81)" (Ética en las comunicaciones sociales, cit., n. 18).

${ }^{26}$ Vid., p. ej., su artículo "The Spiral of Silence. A Theory of Public Opinion", en Journal of Communication, 1974, n. 24, pp. 43-51.
} 
da, tiene de suyo un valor especial. Creo que a esto se refiere Lewis en la cita del principio, cuando afirma que la prensa semanal ha contribuido a cambiar el criterio por el que se juzgan las ideas: por su novedad o por la popularidad de la que gozan, más que por su verdad o bondad intrínsecas. Tradicionalmente, los medios han competido más por la celeridad en dar cuenta de los acontecimientos, que por la calidad de su tratamiento informativo. El empeño de los medios por captar y mantener el interés del público ha instaurado una "lógica de la temporalidad", que conduce casi inevitablemente a una forma superficial de abordar los asuntos, dado que la velocidad a la que se suceden impide profundizar en ellos ${ }^{27}$.

Esta acusada tendencia de los medios a poner el acento en lo novedoso y sensacional -en detrimento de asuntos más importantes a largo plazo, pero menos llamativos-, instaura en la sociedad el imperio de lo efímero, es decir, una mentalidad trivializadora y superficial, que tiende a la simplificación de los problemas y a transmutar en el público el afán de saber por la sed de curiosidades. Esta tendencia de los medios a la banalización y a la superficialidad fortifica la pereza intelectual y el "pensamiento débil", tan característico de la postmodernidad: deteriora el juicio crítico, satura las capacidades cognoscitivas y produce rechazo hacia lo abstracto y lo no útil. No en balde los sociólogos de la comunicación vienen hablando desde hace décadas del "efecto narcotizante" de los medios ${ }^{28}$. Además, el gusto por la espectacularidad no sólo lleva a confundir lo esencial y lo accesorio, sino que, además, invita a las personas a regir su vida más por sensaciones y sentimientos de estabilidad precaria, que por el ejercicio de la inteligencia y de la voluntad.

Esta "lógica de la temporalidad" por parte de los medios no puede desligarse de lo que es, en buena medida, su causa: la "lógica del mercado". Si bien es verdad que los medios prestan grandes servicios a la sociedad, no es menos cierto que su labor no es tan altruista como algunas de sus grandes declaraciones programáticas pretenden, a veces, hacernos creer. Es obvio que los medios no son instituciones filantrópicas, sino empresas que persiguen el lucro económico. De ahí que se muevan por objetivos comerciales en un mercado fuertemente competitivo, lo que, por lo general, les lleva a considerar como valor supremo lo que agrada al público, a pesar de que sea nocivo para su desarrollo como personas ${ }^{29}$. Aunque el logro del beneficio no esté necesariamente reñido con el

\footnotetext{
${ }^{27}$ Esto explica también los sorprendentes silencios en los que caen colectivamente los medios, por ejemplo, respecto a situaciones de crisis (pasado cierto tiempo, aunque la situación no haya mejorado sustancialmente, no vuelven a ocuparse de ellas).

${ }^{28}$ Esta expresión fue acuñada en 1948 por Robert K. Merton y Paul Lazarsfeld con un sentido eminentemente político. Con ella se referían al adormecimiento y la apatía de las masas respecto de la acción política, producido por el conocimiento de la realidad política a través de los medios: "El ciudadano interesado e informado puede sentirse satisfecho por todo lo que sabe sin darse cuenta de que se abstiene de decidir y de actuar [...]. Llega a confundir el conocer los problemas diarios con el hacer algo al respecto" (LAZARSFELD, P. y MERTON, R., "Mass Communication, Popular Taste and Organized Social Action", en BRYSON, L. (ed)., The Communication of Ideas, Nueva York, Harper, 1948, pp. 95-118; cit. por WOLF, M., La investigación de la comunicación de masas, Barcelona, Paidós, 1987, pp. 75-76). Aunque estos autores se referían principalmente a la actividad política del fenómeno, creo que la tesis puede hacerse extensiva a la influencia de los medios en otros aspectos de la vida, particularmente en los relativos al cultivo de la inteligencia.

29 Piénsese, por ejemplo, en las dañinas consecuencias que tiene para amplios sectores de la población -no sólo infantil- la representación inadecuada y constante de actos inmorales de todo género, en particular, de carácter violento y sexual. $O$, en la negativa influencia de programas televisivos banales, que, en el mejor de los casos, hacen perder el tiempo y, en el peor, fomentan una mentalidad superficial y frívola en el público.
} 
respeto de valores genuinamente humanos ${ }^{30}$, de hecho se acaba imponiendo la lógica del éxito fácil. Ésta conduce, con demasiada frecuencia, a explotar los aspectos más sensacionales de las cosas, apela a sentimientos y pasiones no siempre nobles ${ }^{31}$, y evita lo que requiera mucho esfuerzo intelectual. De esta manera, la cosmovisión implícita que subyace en los contenidos ofrecidos a diario por los medios se rige predominantemente por los valores de placer, dinero o poder.

\section{Refuerzo de la mentalidad empírico-positivista y relativista}

Finalmente, los medios tienden, por lo general, a fomentar la mentalidad empírico-positivista, a la que me he referido anteriormente. La teoría de la objetividad, que ha marcado el funcionamiento de los medios en el último siglo ${ }^{32}$, sigue sosteniendo la necesidad de separar hechos y valores $^{33}$. Al aceptar como válida esta distinción, central en el pensamiento positivista, se da carta de naturaleza a una parte esencial de los principios epistemológicos de aquél, antes aludidos. Según éstos, sólo se puede tomar como verdadero lo empíricamente verificable, es decir, las proposiciones referentes a hechos del mundo físico. Por el contrario, los juicios relativos a asuntos sociales y de orden espiritual son tomados por subjetivos, es decir, simples opiniones o preferencias inverificables, carentes de validez veritativa ${ }^{34}$.

Esta idea, que ha calado hondo en la sociedad a lo largo del siglo XX, es continuamente reforzada, sobre todo de manera implícita, en la mente de muchas personas por parte de los medios, hasta el punto de que resulta muy difícil sustraerse a ella y a sus presupuestos. Los medios se nutren de la mentalidad cientifista dominante y, al mismo tiempo, la robustecen a cada paso: sólo presen-

\footnotetext{
${ }^{30}$ Hay muchos ejemplos que podrían citarse como prueba. Por ceñirme sólo a un campo, el audiovisual, baste citar películas todavía en cartelera como Harry Potter y, sobre todo, El Señor de los anillos, que han sido dos de los más grandes éxitos de todos los tiempos, sin dejar de ser a la vez dos películas muy positivas en cuanto a la visión que ofrecen del hombre.

31 "La crítica condena con frecuencia la superficialidad y el mal gusto de los medios de comunicación que, sin estar obligados a la estrechez de miras o la uniformidad, no deberían tampoco caer en la vulgaridad o la degradación. No sirve de excusa afirmar que los medios de comunicación social reflejan las costumbres populares, dado que también ejercen una poderosa influencia sobre esas costumbres, $y$, por ello, tienen el grave deber de elevarlas y no degradarlas" (Ética en las comunicaciones sociales, cit., n. 16).

32 Vid. el excelente estudio histórico de MINDICH, D., Just the Facts. How Objectivity Came to Define American Journalism, Nueva York, New York University Press, 1998.

${ }^{33}$ Baste considerar que el paradigma todavía hegemónico en el ámbito profesional de los medios sigue siendo —al menos, nominalmentela teoría de la objetividad. Hay diversos estudios con base empírica sobre la mentalidad profesional dominante en España. Vid., p. ej., CANEL, M. J. y SÁNCHEZ-ARANDA, J.J., "La influencia de las actitudes profesionales del periodista español en las noticias", Anàlisi, 1999, vol. 23, pp. 151-170; CANEL, "La objetividad periodística en campaña electoral: las actitudes profesionales de los periodistas de TVE 1 y Antena3 en las elecciones de 1996", ZER. Revista de Estudios de Comunicación, vol. 2, 1997, pp. 55-70 y MUNOZ-TORRES, J.R., "Concepciones epistemológicas implícitas en los libros de estilo de El País, El Mundo y ABC", ZER. Revista de Estudios de Comunicación, vol. 9, 2000, pp. 277-318

${ }^{34}$ Vid., p. ej., COMTE, A., Discours sur l'esprit positif, 1844. Cfr., por ejemplo, la p. 54 de la trad. esp.: Discurso sobre el espíritu positivo,
} Madrid, Alianza Editorial, 1988. 
tan como verdadero aquello que está respaldado por la experiencia de una $\mathrm{u}$ otra manera (testimonio de testigos, opiniones de expertos, resultados de experimentos). Aquello no demostrable experimentalmente, o sin apoyo en la experiencia, suele aparecer asociado con lo irracional, esotérico o, cuando menos, dudoso. En este apartado suelen quedar incluidas las doctrinas filosóficas o las creencias religiosas, presentadas con frecuencia como reliquias de un pensamiento mítico caduco ${ }^{35}$.

Como hemos visto antes, la mentalidad empírico-positivista se da unida a la de índole relativista acerca de asuntos no verificables, de carácter intelectual o espiritual. $Y$ así ocurre también en los medios, que, nuevamente, están influidos por las ideas socialmente dominantes y, al hacerlas propias, contribuyen a fortalecerlas ${ }^{36}$. Éstos no suelen hacer profesión declarada de relativismo o escepticismo, pero su discurso sobre lo que no es objeto de conocimiento experimental tiende a legitimar implícitamente esos postulados. Esto se aprecia en varios modos de actuación. Ofreceré sólo un ejemplo.

En primer lugar, las tesis latentes en los textos que forman parte de los (mal) llamados "géneros de opinión". Éstos suelen regirse por una doble premisa implícita aceptada como axiomática: a) no existe ninguna verdad absoluta $y$, en consecuencia, b) todas las opiniones son relativas a cada persona e igualmente válidas (porque no es posible determinar la verdad que encierran). De ahí que los medios tiendan a exonerarse de toda responsabilidad en cuanto a los artículos de opinión, alegando -con parte de verdad, pero no con toda la verdad-que ésta corresponde en exclusiva a sus autores (como si éstos no fueran previamente elegidos por el medio y no estuvieran influidos, además, por las expectativas que éste tiene sobre su trabajo). Además, como -para la mayoría de los medios- las opiniones no son verdaderas ni falsas, sensatas o descabelladas, sobre ellas sólo cabe una respetuosa discrepancia, a la postre irrelevante.

En coherencia con este planteamiento, la única exigencia que los medios aceptan respecto a las opiniones es el pluralismo, entendido habitualmente no como medio para esclarecer la validez de unas afirmaciones mediante su confrontación con otras, sino como simple oferta heterogénea que proporcione margen al lector o espectador para elegir la que más concuerda con sus propios puntos de vista. De esta manera, algo tan positivo como el pluralismo se puede tornar negativo, si va asociado a premisas relativistas o escépticas ${ }^{37}$. Los talk-shows televisivos son un buen ejemplo -representativo de otros muchos que se pueden encontrar- de esta posición.

\footnotetext{
${ }^{35}$ Contrasta sorprendentemente que los medios tiendan a menospreciar o ignorar el conocimiento que se basa en la fe religiosa, es decir, en la autoridad de Dios, cuando ellos mismos no podrían operar sin el conocimiento que se basa en la fe humana, es decir, en la confianza que les merecen las fuentes (sean agencias, corresponsales, testigos entrevistados, otros medios, etc.). La pretensión empírico-positivista se compadece mal -a mi entender- con esta inevitable dependencia de la confianza en el conocimiento ajeno.

${ }^{36}$ Una valiosa exposición crítica de la traslación de los postulados positivistas al ámbito periodístico en: GALDÓN LÓPEZ, G., Desinformación, Pamplona, Eunsa, 1994.

${ }_{37}$ Una forma de relativismo son las tesis consensualistas: dado que no hay posibilidad de alumbrar la verdad en asuntos no instrumentales, la única aspiración posible en los debates públicos es el logro del máximo consenso, no a partir de imposibles criterios de verdad sobre el ser de las cosas, sino alcanzado por el mero asentimiento arbitrario de la mayoría.
} 


\section{PARA NO CONCLUIR}

Ante el problema planteado, abocetado sólo a grandes trazos, tal vez nuestra mente -siguiendo la estrategia del mismísimo Escrutopo- podría sugerirnos diversos calificativos para rechazarlo: "pesimista", "exagerado", "radical", "católico"... Probablemente, el lector que haya llegado a este punto lo habrá hecho después de haber superado con éxito ese eficaz procedimiento de engaño y distracción. Si, en cambio, ha caído en él -confirmando así la verdad de la observación inicial de Lewis-, entonces tales adjetivos, u otros parecidos, le habrán disuadido de hacerse la pregunta realmente central sobre lo tratado: qué grado de verdad encierra.

Con independencia de una u otra situación, sólo hay un procedimiento -a mi juicio- de combatir la hábil estrategia de Escrutopo y sus aliados: atreverse nuevamente a pensar con rigor, yendo al fondo de las cuestiones, sin dejarse seducir por la descalificación fácil, ayuna de argumentos. Si es verdad que la relación postmoderna entre pensar y obrar está marcada por la incoherencia, quizá la única manera de superarla sea recuperar el terreno cedido por la inteligencia en favor de la voluntad y la sensibilidad, que aspiran a una hegemonía omnímoda. En otras palabras, la superación de la crisis de la postmodernidad exige, para empezar, un diagnóstico certero y decidido de sus causas, seguido de una revitalización profunda del "pensamiento fuerte" abandonado (metafísica y epistemología realistas), fundamento de nuestra civilización desde los griegos. Obviamente -sobre la base de lo ya dicho-, la tarea no es exclusivamente intelectual, pues difícilmente podrá el pensamiento retomar su misión directiva, si la voluntad o la sensibilidad lo condenan sistemáticamente al silencio. Pero, no menos difícil es que éstas renuncien al poder conquistado, si la inteligencia no muestra que ambas por sí solas están ciegas y abocan a una vida escasamente humana.

Al afirmar esto, no estoy proponiendo un retorno acrítico y anacrónico al pasado, sino rescatar, repensándolo, lo más valioso de él con vistas al presente y al futuro. Si la inteligencia humana en su dimensión de razón instrumental tiene enorme confianza en sí misma -a veces excesiva-, no hay motivo para dudar de su capacidad en su dimensión especulativa. Si, en los siglos precedentes, ésta ha mostrado su vigor -aunque con la limitación de todo lo humano-, igualmente puede seguir haciéndolo en el presente. Decretar, pues, de forma gratuita su insuficiencia sería quedarse definitivamente a oscuras.

Recuperar el rumbo perdido y avanzar por él no es tarea que admita recetas fáciles, ni que pueda realizarse a corto plazo. Al contrario, pienso que exigirá el esfuerzo colectivo de varias generaciones para recobrar algunas evidencias perdidas (singularmente las relativas a las categorías de la contradicción) y para caer en la cuenta de los errores y quiebras a los que conducen las actuales corrientes filosóficas escépticas, relativistas y empiristas, que imperan en la mayor parte del mundo occidental. En esta labor, las élites intelectuales habrán de desempeñar -como hasta ahora- un papel de guía. Ahora bien, su eficacia será mínima sin la colaboración de los medios, dado que el cambio que se precisa es a gran escala. De ahí la enorme responsabilidad de todos los que trabajan en los medios, o forman a sus futuros profesionales $o$, de una $u$ otra manera, tienen 
relación con su función en la sociedad. Pienso que, con sólo empezar a reflexionar sobre estas cuestiones, hemos ya empezado a dar los primeros pasos para derrotar la estrategia de Escrutopo, hasta ahora acreditadamente eficaz.

\section{REFERENCIAS BIBLIOGRÁFICAS}

- Alonso, C. J., (1999): La agonía del cientifismo, Pamplona: Eunsa.

- Aristóteles, Ética a Nicómaco, ed. de M. Araujo y J. Marías (1985): Madrid: Centro de Estudios Constitucionales.

- Aristóteles, Metafísica, ed. de García Yebra, V. (1990), Madrid: Gredos.

- Canel, M.J. (1997): "La objetividad periodística en campaña electoral: las actitudes profesionales de los periodistas de TVE 1 y Antena3 en las elecciones de 1996", ZER. Revista de Estudios de Comunicación, vol. 2, pp. 55-70.

- Canel, M. J. y Sánchez-Aranda, J.J. (1999): "La influencia de las actitudes profesionales del periodista español en las noticias", Anàlisi, vol. 23, pp. 151-170.

- Choza, J. (1973): "Elogio de los grandes sinvergüenzas", en Nuestro Tiempo, nn. 229-230, pp. 83-87.

- Comte, A. (1844) : Discours sur l'esprit positif, trad. esp. (1988): Discurso sobre el espíritu positivo, Madrid: Alianza Editorial.

- De Fleur, M. y Ball-Rokeach, S. (1993): Teorías de la comunicación de masas, Bar-celona; Paidós.

- Eco, U. (1968): Apocalípticos e integrados ante la cultura de masas, Barcelona: Lu-men.

- Eco, U. (1983): El nombre de la rosa, Barcelona: Lumen.

- Galdón López, G. (1994): Desinformación, Pamplona: Eunsa.

- Juan Pablo II (1998): Carta encíclica Fides et Ratio.

- Lewis, C.S. (1991): The Screwtape Letters, Londres: HaperCollins (ed. Española (1998): Cartas del diablo a su sobrino, Madrid: Rialp).

- Macintyre, A. (1987): Tras la virtud, Barcelona: Crítica (Grijalbo).

- Mindich, D. (1998): Just the Facts. How Objectivity Came to Define American Journalism, Nueva Cork: New York University Press.

- Muñoz-Torres, J. R. (2002): "Objetividad y verdad. Sobre el vigor contemporáneo de la falacia objetivista", Revista de Filosofía de la Universidad Complutense de Madrid, vol. 27, n. 1, pp. 161-190.

- Muñoz-Torres, J.R. (2000): "Concepciones epistemológicas implícitas en los libros de estilo de El País, El Mundo y ABC", ZER. Revista de Estudios de Comunicación, vol. 9, pp. 277-318.

- Nagel, Th. (2000): La última palabra, Barcelona: Gedisa. 
- Noelle-Neuman, E. (1974): "The Spiral of Silence. A Theory of Public Opinion", en Journal of Communication, n. 24, pp. 43-51.

- Pontificio Consejo Para Las Comunicaciones Sociales (2000): Ética en las comunicaciones sociales.

- Putnam, H. (1988): Razón, verdad e historia, Madrid: Tecnos.

- Sartori, G., Homo videns (1988). La sociedad teledirigida. Madrid: Taurus.

- Vattimo, G. (1987): El fin de la modernidad. Nihilismo y hermenéutica en la cultura posmoderna, Barcelona: Gedisa.

- Vicente Arregui, J. (1981): "La condición de posibilidad del conocimiento práctico", en Anuario Filosófico, vol. XIV, n. I, pp. 115-124.

- Wolf, M. (1987): La investigación de la comunicación de masas, Barcelona: Paidós. 